\section{Crichton Royal}

Dear Sirs

The thumb-nail historical sketch of the Crichton Royal (Psychiatric Bulletin, June 1989, 13, 294-295) evoked very happy memories of a war-time stint there.

Shortly after the outbreak of war in 1939, the newest ward-complex at the Crichton, a little remote from the Victorian main buildings, was designated the 'Military Hospital, Dumfries', for the reception, investigation, and treatment of officer patients who had become psychiatric casualties. Dr McCowan got out his old 1914-18 uniform, altered the buttons and badges and became Lt-Col P. K. McCowan, OC Military Hospital, Dumfries, as well as Physician Superintendent of the Crichton Royal Hospital itself.

In 1941, by the desperate expedient of falling off the Rock of Gibraltar, I was invalided home, and when fit for light duty, was granted my request to be posted to a psychiatric unit. No junior officer ever had a more fortunate posting. I found a clinical/ administrative model in the shape of 'PK' himself; civilian doctors of the Crichton served the military patients, and there was Willi Mayer-Gros, everpatient and tolerant of an enthusiastic neophytic Captain, prepared to teach him about schizophrenia, and insulin therapy; Dennis Carrol, of the Institute for the Study and Treatment of Delinquency, was in the uniform of a Major; to him, rank meant nothing, and he permitted me to observe him in short-term psychotherapy, including hypnotically-induced abreaction, of acute battle neuroses and conversion hysterias; of enormous use later, thousands of miles away. Most clearly and affectionately remembered was Erwin Stengel, who on Sunday evenings was 'At Home' to doctors, both military and civilian. We literally sat at his feet, and listened to good music and great wisdom, while Mrs Stengel pressed upon us delicious pastries and superb coffee.

These giants had the courtesy that goes with greatness of spirit, and for many years afterwards would greet me with warm enquiries, and encouragment, about my professional career.

Never was a three months convalescence more productively and enjoyably spent, and it was almost with reluctance that I was restored to 'Category A', and left the Mental Hospital to return to the higher lunacy of active service.

18 Heathermount Drive

Patrick C. McGrath Crowthorne, Berks RG11 6HN

\section{Psychotherapy on the NHS}

\section{Dear Sirs}

In his consideration of the future of psychotherapy in the NHS (Psychiatric Bulletin, April 1989, 13,
432-34) Dr Obholzer suggested ways in which the NHS psychotherapist might make a contribution in the post-Griffiths era. He neglected to address the issue of cost-effectiveness which seems to be essential in the current economic climate. If, as he suggests, the NHS psychotherapist has a role in training in psychotherapy and provision of psychotherapy services, the type of treatment used must be shown to be effective. In the past evaluation of psychoanalytic therapy has not been seen as a priority, but it may need to become so in the future.

Dr Obholzer seems to suggest that as psychiatrists reduce prescription of benzodiazepine drugs psychodynamic therapists ought to step in to treat the neurotic patients who would otherwise have received tranquillisers. There are, however, other forms of short term psychological treatments for anxiety and depression which have been shown to be effective in randomised controlled trials. Cognitive and behavioural therapies provide relatively brief interventions for phobias, obsessive compulsive disorders, panic disorder, generalised anxiety and depression. While the value of psychoanalytically oriented therapies in the NHS is clear, it is more questionable that NHS psychotherapists should be drawn exclusively from this discipline. It is now time to take a fresh look at psychotherapy provision in the light of research on psychotherapies currently available.

S. MOOREY S. GREER

Cancer Research Campaign

Psychological Medicine Group

The Institute of Cancer Research and

The Royal Marsden Hospital

London SW3 6JJ

\section{Specialty status of Old Age Psychiatry}

\section{DeAr Sirs}

As Chairman of the Section, I am constantly asked whether following Council's recommendation that Old Age Psychiatry should be regarded as a specialty, it actually is one.

I write therefore to inform all members and fellows of the College that the specialty status of Old Age Psychiatry has been conceded by the Department of Health (1989).

Chairman

Professor Brice PItT

Section for the Psychiatry of Old Age

\section{Reference}

Department of Health (1989) Circular letter to Specialists in Community Medicine at the English Regional Health Authorities, and Wales, 21.7.89. (Copies available from Jean Wales at the College). 